\title{
A gestão de conflitos em microempresas familiares: um estudo de múltiplos casos na cidade de Olinda
}

Apesar da grande importância das microempresas para a economia do país, muitas delas enfrentam sérias dificuldades para se manterem em operação, entre elas os conflitos que ocorrem dentro da organização. As microempresas familiares apresentam conflitos de diferentes tipos, origens e níveis, causando mudanças significativas, que afetam diretamente na produtividade, no relacionamento e na dinâmica dos envolvidos. A depender da forma como esses conflitos são, podese ter resultados positivos e negativos. A pesquisa teve como objetivo identificar os conflitos nas microempresas familiares e suas possíveis soluções. Partindo de uma pesquisa exploratória e utilizando-se da pesquisa qualitativa, foram realizadas entrevistas semiestruturadas com gestores de microempresas familiares na cidade de Olinda. Concluiu-se que a origem dos conflitos nas empresas entrevistadas deu-se a partir da não separação entre relação profissional e pessoal e, para gerenciar esses conflitos, as empresas utilizaram o diálogo, que possibilitou a aprendizagem e acordos, que beneficiaram ambas as partes, mudando o clima organizacional e a dinâmica entre os membros da família.

Palavras-chave: Gestão de Conflitos; Solução de conflitos; Microempresas familiares.

\section{Conflict management in family micro enterprises: a study of multiple cases in the city of Olinda}

Despite the great importance of micro-enterprises to the country's economy, many of them face serious difficulties to remain in operation, including conflicts that occur within the organization. Family micro-enterprises have conflicts of different types, origins and levels, causing significant changes, which directly affect productivity, relationships and the dynamics of those involved. Depending on how these conflicts are, you can have positive and negative results. The research aimed to identify conflicts in family micro-enterprises and their possible solutions. Starting from an exploratory research and using qualitative research, semistructured interviews were conducted with managers of family micro-companies in the city of Olinda. It was concluded that the origin of the conflicts in the interviewed companies was due to the lack of separation between professional and personal relationship and, to manage these conflicts, the companies used dialogue, which enabled learning and agreements, which benefited both parties, changing the organizational climate and dynamics among family members.

Keywords: Conflict management; Conflict resolution; Family micro-enterprises.

Topic: Comportamento Organizacional

Reviewed anonymously in the process of blind peer.
Received: 11/04/2021

Approved: 08/06/2021 lasmin Luz de Paulo

Universidade Federal de Pernambuco, Brasil

iasmin luz@hotmail.com

Karoline Gomes Silva

Universidade Nove de Julho, Brasil

http://lattes.cnpq.br/4677912577370513

karolinegomesgs@gmail.com

Humberto Caetano Cardoso da Silva (iD

Universidade Federal de Pernambuco, Brasil

http://lattes.cnpq.br/4594928852071554

http://orcid.org/0000-0001-9584-4465

humberto.ccs@gmail.com
Referencing this:

PAULO, I. L.; SILVA, K. G.; SILVA, H. C. C.. A gestão de conflitos em microempresas familiares: um estudo de múltiplos casos na cidade de Olinda. Revista Brasileira de Administração Científica, v.12, n.2, p.379-390, 2021. DOI: http://doi.org/10.6008/CBPC2179$\underline{684 X .2021 .002 .0030}$ 


\section{INTRODUÇÃO}

As Micro e Pequenas Empresas (MPE) possuem grande relevância na economia brasileira, afetando diretamente o desenvolvimento econômico do país. Segundo o IBGE, só no segundo trimestre de 2019, 1,2 milhões de pessoas entraram para a lista de desempregados no Brasil sendo, ao todo, 13,4 milhões. Por consequência da alta taxa de desemprego no país, o empreendedorismo torna-se uma opção comum como uma fonte de renda.

Neste contexto, é possível perceber a predominância da participação familiar no estilo de empresas fundadas. Uma pesquisa realizada em 2016, mostra que 52\% das Micro e Pequenas empresas no Brasil são do tipo familiares, ou seja, possuem sócio ou empregado parente do proprietário.

Segundo o Sebrae, ter um membro da família como sócio ou empregado é realidade entre a maioria dos pequenos negócios. A maioria dos problemas na empresa familiar envolve disputas por dinheiro ou poder e está diretamente ligada à relação entre os membros da família.

Apesar da importância das micro e pequenas empresas, percebe-se que, assim como acontece nas empresas de médio e grande porte, os conflitos estão presentes no dia a dia da organização, afetando diretamente o seu desempenho. Para Alméri et al. (2014) "o conflito é um produto inevitável na vida organizacional".

Nesta linha Chiavenato (2014) afirma que:

A palavra 'conflito' está ligada ao desacordo, discórdia, divergência, dissonância, controvérsia ou antagonismo. Para que haja conflito, além da diferença de objetivos e interesses, deve haver necessariamente uma interferência deliberada de uma das partes seja indivíduo ou grupo - tenta alcançar seus próprios objetivos interligados com alguma outra parte, a qual interfere na sua busca de atingir os objetivos.

Alméri et al. (2014) argumentam que existem três tipos de conflitos dentro de uma organização: os de relacionamento, por conta de diferenças de valores, pois cada pessoa pode possuir valores diferentes, criando assim, uma situação de conflito por causa dessas diferenças; conflitos de tarefas, que está relacionado ao cumprimento das metas e ao conteúdo do trabalho; e conflito de processo, que é como o trabalho será realizado pelos funcionários.

Portanto, o conflito é algo dinâmico que gera uma reação, causando dois tipos de efeitos. Num ambiente onde a competitividade é estimulada, pode-se gerar conflitos positivos, que criam um ambiente de curiosidade nos colaboradores devido ao estimulo à competitividade, fazendo com que os indivíduos busquem desenvolver suas habilidades; em contrapartida, o sentimento de frustração num ambiente competitivo pode gerar um conflito negativo, afetando o rendimento em suas tarefas, causando um malestar nos colaboradores (BONETTO et al., 2017).

Dentro da ótica apresentada, foi buscado verificar a ocorrência destes conflitos, além de identificar possíveis soluções para empresas familiares que passam ou passaram por situações de conflito. De acordo com Adachi (2006):

As empresas familiares possuem o que podemos denominar de atributos bivalentes, isto é, características que podem ser, ao mesmo tempo, vantagens ou desvantagens dependendo da forma como as empresas são conduzidas, como, por exemplo, a simultaneidade de 
papéis desempenhados pelos membros da empresa familiar, o envolvimento emocional e afetivo das pessoas que nela trabalham, a identidade compartilhada dos parentes, sua história de vida comum e sua linguagem particular.

A partir do exposto, a questão da pesquisa que norteou o presente trabalho foi: como as microempresas familiares do setor de varejo gerenciam seus conflitos internos?.

A fim de responder à questão da pesquisa, o presente artigo está organizado da seguinte forma: após apresentada a introdução, abordam-se os fundamentos teóricos sobre a definição de microempresa (ME), define-se o que são empresas familiares e a importância da gestão de pessoas nestas empresas, o que são conflitos e suas principais causas.

\section{REVISÃO TEÓRICA}

\section{A microempresa}

De acordo com a Lei Complementar $n^{\circ} 123$, de 14 de dezembro de 2006, as micro e pequenas empresas possuem um tratamento diferenciado em relação as outras de diferentes portes. Por causa do total de sua receita bruta anual, as MPE se encaixam no Simples Nacional, uma maneira de arrecadação de tributo simplificada.

Para uma empresa ser considerada uma microempresa é necessário que está tenha algumas características que a diferencie de outros tipos de empresas, por exemplo, o faturamento bruto anual deve ser inferior ou igual a $360.000,00$ (RODRIGUES et al., 2017).

Outra característica das microempresas se dá pelo total de funcionários permitidos. Segundo o Oliveira (2014), para ser considerada uma ME é necessário que o número de funcionários seja inferior ou igual a 19, na área industrial e de construção, e na área comercial e serviços o número de funcionários deve ser até 9.

O maior número de empresas registradas no Brasil são de PME. De acordo com o Sebrae, no Brasil, existe 6,4 milhões de estabelecimento, $99 \%$ são de micro e pequenas empresas. Mais da metade dos empregados que trabalham com carteira assinada, no setor privado, são de micro e pequenas empresas.

As microempresas possuem um papel fundamental no desenvolvimento econômico do Brasil. Nesta linha, Garuffe et al. (2017) pontuam que as micro e pequenas empresas respondem por $27 \%$ do PIB do país, sendo que $19 \%$ dessas empresas estão localizadas na região Nordeste do Brasil, ficando atrás apenas do Sudeste que possui $50 \%$.

Para Fernandes et al. (2019), com um crescente número de MPE no brasil, novos empregos são criados, afetando positivamente a renda da população brasileira. Além disso, essas empresas ocupam segmentos e conseguem atender demandas que as de grande porte não o fazem.

Entretanto, Fernandes et al. (2019) afirmam que a dificuldade de sobrevivência dessas empresas é um fator preocupante e que só nos primeiros meses de 2017, mais de 60.000 MPE fecharam as portas. Segundo Silva et al. (2015b), do total de MPE que existem no brasil, 22\% delas não conseguem permanecer ativas no mercado por mais de dois anos. 
Os fatores que levam as micro e pequenas empresas a terem um nível elevado de mortalidade são diversos. Para Rodrigues et al. (2017) destacam-se: a escassez de clientes; a influência ou a ausência de capital de giro; o compromisso com carga a tributária; e a inexperiência do empreendedor.

O planejamento estratégico também é um fator determinante para que as MPE possam sobreviver. De acordo com Ruzzão et al. (2017), essas empresas possuem uma enorme dificuldade quando se trata de gestão e planejamento estratégico, por conta das limitações de pessoal capacitado, em especial o proprietário.

Os referidos autores também dizem que esse modelo de gestão causa uma dependência das MPE sobre seu proprietário, ao passo que a sobrevivência depende apenas dele e deu seu conhecimento. Essa dependência centralizada na gestão das micro e pequenas empresas é um dos fatores que as diferenciam das empresas de médio e grande porte.

\section{Microempresa Familiar}

A gestão familiar é o modelo mais comum quando se trata de gestão em microempresas. Segundo Silveira (2011), esse modelo de empresa possui um pequeno capital de giro, ao passo que a inovação não é algo recorrente, com pouco investimento em tecnologias. Também não possui divisões de tarefas específicas, pois o próprio proprietário, que também é o gestor, participa e faz a maioria das funções necessárias.

Corroborando com esse pensamento, Fernandes et al. (2019) dizem que grande parte das microempresas, por serem fundadas e administradas por uma família, não conseguem separar a vida pessoal da vida profissional.

Para Werner (2004), a empresa onde o seu fundador a desenvolveu e, no decorrer do tempo, a formou com familiares, caracteriza-se como empresa familiar. Já para Mamede et al. (2012), é reconhecido como familiar as empresas em que suas quotas ou ações estejam sob o controle de uma família, podendo ser administradas por seus membros, ainda que com o auxílio de gestores profissionais.

Abreu et al. (2014) afirma que empresa familiar se inicia a partir do empreendedorismo de seu fundador que, possuidor de uma ideia, parte em busca da realização de sua aspiração pessoal. A história da empresa é, em geral, fruto da experiência de vida de seu próprio fundador, de suas origens e de seus talentos pessoais. O mesmo autor aborda que, um dos relevantes aspectos característicos das empresas familiares está na premissa de que as decisões no âmbito familiar são pautadas, em regra, no sentimento, na pessoalidade e na tradição, o que contrapõe com a racionalidade e eficiência que deve prevalecer na prática empresarial.

Para Velloso et al. (2014), a microempresa não necessariamente deve ser formada apenas por pessoas da mesma família. Ela tem a sua origem através de um grupo familiar, mas a sua composição ao logo do tempo, pode variar.

Limárcio et al. (2015) afirma que o líder de uma empresa familiar deve estar preparado para lidar com todos os tipos de situações que o mercado impõe inclusive conflitos familiares dentro da própria empresa, o que não é uma tarefa simples, pois ele estará no meio de um conflito familiar que envolve os 
negócios da empresa.

Nesta linha, Fernandes Neto (2005) prega que um líder, no momento de conflito, utilizaria:

Um certo feeling (tato, sensibilidade), embora, em alguns momentos, não será, por si só, suficiente para alcançar uma solução eficiente e eficaz, que atenda a todas as partes envolvidas.

Assim, enquanto o conflito não estiver solucionado, ele tende a se ampliar por meio da procura de novos aliados. Pode-se fazê-lo terminar espontaneamente ou à custa de arbitragens ou mediações, sendo sempre melhor induzir o encerramento do conflito do que deixar a situação se deteriorar (SILVA et al., 2015a).

\section{Conflitos}

O conflito é definido por Dubrin (2006) como sendo um choque de personalidade entre duas pessoas, baseado em diferenças de atributos, preferências, idade, raça, etnia, interesses, valores e estilos, que leva a oposição ou resistência podendo acarretar a elevação de alguma tensão.

Adicionalmente, Nascimento et al. (2012) pregam que o conflito se manifesta a partir das diferenças de valores, vaidades entre indivíduos e seus pares, equipes de trabalho, dirigentes, sociedades, organizações e seus colaboradores. É a contradição entre os interesses de quem detém o poder com os interesses dos excluídos.

Existem diversos tipos de conflitos presentes no ambiente social, organizacional e cultural. Chiavenato (2014) mostra que existem duas formas de conflitos: o interno, comumente conhecido como intrapessoal; e o conflito externo, que é dividido em algumas categorias, como por exemplo: conflito interpessoal, intragrupo e intergrupal.

Nesta linha, Carvalho (2019) define que conflito interno ocorre consigo mesmo, de forma individual, e não precisa, necessariamente, de socialização com outras pessoas para manifestar-se. Este tipo de conflito parte de emoções próprias, do estado psicológico de cada um. O conflito interno afeta a capacidade de decisão, tornando mais difícil a possibilidade de um indivíduo fazer escolhas.

Segundo Souza et al. (2014), os conflitos interpessoais fazem parte de qualquer organização, dão-se início a partir da comunicação e interação entre as pessoas que possuem ideias, costumes e culturas diferentes entre si, podem se manifestar tanto nas discussões profissionais, como também nas discussões pessoais, sendo os conflitos interpessoais também reconhecidos como conflitos de relacionamento.

Esses conflitos podem apresentar-se em três níveis diferentes, segundo Chiavenato (2014), o primeiro nível é o percebido, onde os indivíduos estão cientes de suas diferenças e que isso pode vir a ocasionar um conflito; o segundo nível é o experienciado, onde os indivíduos têm sentimentos hostis e não agradáveis um pelo outro, porém isso não é revelado; por último, o nível manifestado, onde uma ou ambas as partes expressam suas divergências e seus descontentamentos de maneira aberta.

Para Alméri et al. (2014), alguns conflitos, se bem administrados e gerenciados, podem resultar em consequências positivas para a empresa. Os que ajudam e colaboram com a produtividade e dinâmica na empresa, podendo trazer benefício são chamados de funcionais. Estes podem ocasionar melhorias que 
normalmente estão relacionados com tarefas e processos, tornando-se construtivos para a organização. Já o conflito disfuncional é aquele que atrapalha e prejudica o andamento, produtividade e os objetivos da organização, gerando desperdício de tempo e gasto de energia, que são absorvidos por esses conflitos.

Os mesmos autores também afirmam que o resultado funcional de um conflito está mais presente nos conflitos de processos e tarefas, que estão ligados diretamente à produtividade; já o resultado disfuncional está inserido no conflito interpessoal, onde a interação entre os indivíduos e grupos geralmente afeta a produtividade, trazendo consequências negativas.

Assim, baseado em Chiavenato (2014), Alméri et al. (2014), Souza et al. (2014), o quadro 1 apresenta a composição proposta no presente trabalho, que foi utilizada para a análise dos conflitos em microempresas familiares.

Quadro 1: Tipos e níveis de conflitos nas microempresas.

\begin{tabular}{|l|l|l|l|}
\hline \multirow{2}{*}{ Conflitos Externos } & \multicolumn{2}{|l|}{ Níveis do conflito } & 3o Manifestado \\
\cline { 2 - 4 } & 10 Percebido & 20 Experienciado & \\
\hline Interpessoal (de relacionamento) & & & \\
\hline Intragrupo & & & \\
\hline Intergrupal & & & \\
\hline
\end{tabular}

Fonte: inspirado em Chiavenato (2014); Alméri et al. (2014); Souza et al. (2014).

\section{METODOLOGIA}

A pesquisa foi realizada através de uma abordagem qualitativa, sendo de cunho exploratório, buscando os tipos de conflitos e soluções adotadas pelas empresas participantes do estudo. A coleta dos dados foi realizada a partir de um instrumento semiestruturado.

A pesquisa de campo foi realizada com microempresas familiares do bairro Jardim Atlântico, município de Olinda/PE. Participaram da pesquisa 5 microempresas de comércio, que se encaixam no perfil desejado. Os sujeitos do estudo foram os proprietários e funcionários dessas organizações, que possuem papel estratégico e de tomada de decisão dentro da empresa, tendo também laços familiares. As entrevistas foram realizadas nos meses de outubro de 2019 a fevereiro de 2020.

De acordo com Prodanov et al. (2013), os estudos de caráter exploratório são, em geral, de abordagem qualitativa, utilizam ferramentas como levantamento bibliográfico, estudo de caso, entrevista e análise de exemplos.

O instrumento de coleta de dados do estudo foi a entrevista semiestruturada, contendo cinco questões: Em algum momento você percebeu que a sua opinião e ponto de vista eram diferentes de outra(s) pessoa(s) na empresa e que isso poderia gerar um possível enfrentamento ou animosidade?; Já ocorreu alguma situação em que você ou outra pessoa(s) envolvida(s) nutriu(ram) sentimento(s) negativos como: raiva, insatisfação?; Alguma vez essas diferenças e sentimentos negativos levaram a uma situação de enfretamento ou embate?; De que forma vocês resolveram essa situação?; A partir dessa situação foi possível extrair resultados positivos ou negativos?.

A análise dos dados foi realizada a partir da técnica de análise de conteúdo, utilizando-se da vertente análise proposicional do discurso (BARDIN, 2011). Os elementos utilizados para categorização foram os tipos 
e níveis de conflitos anteriormente apresentados no quadro 1 e identificados nas empresas participantes.

A partir destas perguntas, foi possível identificar qual o tipo e conflito existente, qual o nível que se encontra e possíveis soluções para empresas familiares que passam ou passaram por conflitos.

\section{RESULTADOS E DISCUSSÃO}

Dentre as empresas participantes do estudo foi possível identificar os conflitos do tipo interpessoal e intragrupo, bem como os níveis de conflito percebido, experienciado e manifestado.

\section{Conflito interpessoal}

O conflito interpessoal foi o tipo mais comum encontrado na pesquisa, tendo sido identificado em quatro das cinco empresas participantes. Porém, esse tipo de conflito se apresentou em níveis diferentes. Nas empresas A, B, C e D, foi possível verificar o conflito em seu nível percebido, onde existe diferenças e divergência entre as pessoas e essas diferenças podem levar a um conflito.

O conflito interpessoal pôde ser identificado na afirmação do sujeito $A$, quando este coloca que 'principalmente em questão de horário. Um funcionário que chega bem após o horário dele, aí o outro não concorda'. Para B, a divergência surgiu quando o método de trabalho se tornou divergente, pois a 'questão de preço, arrumação das mercadorias... ocorreu entre eu e meu funcionário'.

Já o sujeito C colocou que seu funcionário é seu filho e que isso afeta na relação de família e trabalho, pois seu funcionário (filho) tem dificuldade em separar essas duas relações: 'Sim. Na verdade, eu trabalho com meu filho, há um bom tempo, por ser meu filho fica uma coisa bem flexível, ele fica meio que acomodado'. Entretanto, o sujeito C está consciente de que essa diferença entre família e funcionário precisa ser estabelecida, para não chegar a um conflito: 'estabelecendo algumas regras para poder a gente trabalhar na boa porque antes de pai e filho, como eu digo a ele, a gente é trabalho, ele tem que levar em consideração isso'.

Da mesma forma que o sujeito B deu exemplo de divergência em relação ao método de trabalho, o sujeito $D$ também faz sua queixa sobre a mesma questão: 'A questão de arrumação, que vejo que um produto deveria ser na frente, aí ele fala que o produto deve ser atrás, aí acaba tendo essas divergências'.

Já o conflito em seu nível experienciado, onde existe sentimentos negativos envolvido entre essas pessoas, foi externado pelos sujeitos $B, C, D$ e $E$.

O sujeito B deu um exemplo em que, por divergência entre ele e um funcionário, por não chegar num senso comum em relação a algo 'isso vem a gerar uma raiva, insatisfação'. $O$ sujeito $C$ apresenta, mais uma vez, agora no nível experienciado, problemas em separar relações de trabalho, dessa vez, entre uma amizade: 'Já aconteceu entre eu e meu filho, já aconteceu entre eu e um rapaz que trabalhou aqui comigo'. C afirma que seu funcionário, que era seu amigo próximo, nutriu sentimentos negativos porque quando recebeu uma ordem, não conseguiu diferenciar as relações: 'ficava parecendo que eu estava exigindo de mais, e eu percebi essa pessoa meio insatisfeita'.

Na empresa D, o entrevistado afirmou que houve sentimentos negativos envolvendo seu funcionário, 
chegando a um ponto em que ele agia com falta de educação 'ele começou a me olhar com outros olhos, sempre que eu falava, ele me respondia com ignorância'. Na empresa $\mathrm{E}$, o entrevistado colocou que seu filho não estava presente numa ocasião onde o cliente precisava ser atendido 'eu tinha que atender o caixa, dar satisfação ao cliente que estava comprando, e no mesmo instante ele não estava para me atender, então isso gera raiva e consequentemente gera conflito'.

O conflito em seu nível manifestado, no qual todas essas diferenças e sentimentos negativos existentes levaram a um nível de enfrentamento ou embate, aconteceu apenas com os sujeitos das empresas De E.

No caso do sujeito D, sua mãe foi a pessoa confrontada devido a uma má conduta dentro da empresa, tratando os clientes de forma inadequada, chegando a um ponto em que o sujeito $D$ viu a necessidade do enfrentamento 'Fui falar a ela que o movimento estava fraco no horário dela, ela ficou chateada ao ponto de dizer que eu procurasse outra pessoa para trabalhar, e que não vinha mais'.

O sujeito da empresa $E$ disse que por conta do funcionário não estar na hora em que o cliente precisava ser atendido, ocasionou uma situação de embate entre os dois 'houve a reclamação, houve essa imparcialidade no comércio, e terminou assim realmente uma discussão' e adicionai ainda que 'compreensão que faltou na hora de atender ao que era para ser atendido'.

\section{Conflito intragrupo}

Para Ribeiro et al. (2017), o conflito intragrupo se caracteriza por haver diferenças e divergências dentro de um mesmo grupo. Foi possível identificar esse conflito nas empresas A e E. No sujeito A, o conflito intragrupo foi encontrado a partir da seguinte afirmação: 'a minha mãe, a gestora, fica chateada tanto comigo, quanto com meu irmão, quando compramos e não avisamos'. Com essa declaração de $A$, foi possível identificar o conflito em seu nível experienciado, pois as pessoas do grupo envolvido criaram e nutriram sentimentos negativos um pelo outro, a partir de suas divergências.

O sujeito $A$ também mostra o conflito intragrupo em outra fala: 'às vezes, meu pai tem um modo diferenciado de se comunicar com o cliente que eu, nem minha mãe e meu irmão concordamos, eu me envolvo e chegamos a debater, bater boca'. Já nesta fala, é possível identificar o conflito em seu nível manifestado, devido ao fato de que as diferenças levaram a uma discussão.

O conflito intragrupo também está presente na empresa $E$, porém, ele é encontrado em seu nível percebido, onde os indivíduos do grupo estão cientes de suas diferenças de opiniões, e que essas diferenças podem gerar um conflito, no futuro. O sujeito E afirma que: 'sempre é aquele ponto de vista deles, que eles não estão trabalhando para estranhos, e como pai e mãe eles sempre tem liberdade de falar, isso atrapalha sim'.

\section{Resoluções}

Para Carvalho (2014), existem formas de resolver os conflitos presentes nas empresas, entre elas estão competição, onde não existe diálogo, apenas o uso de autoridade; acomodação, onde o indivíduo abre 
mão de sua visão e opiniões para agradar a outra pessoa; afastamento, cujo o interesse é manter-se longe do conflito, ignorando-o; acordo, onde os indivíduos chegam no meio termo, através do diálogo, em busca de uma solução rápida; e a colaboração, onde os indivíduos trabalham juntos, conversando e dialogando, para achar uma solução que satisfaça ambas as partes.

Entretanto, não existe uma solução certa para cada tipo de conflito, pois eles podem ser resolvidos de maneiras diferentes. Porém, para Ruffatto et al. (2017), a falta de diálogo dificulta a resolução de conflito nas empresas.

O recurso mais utilizado pelas cinco empresas entrevistadas foi o diálogo. Esse recurso sempre foi a primeira opção utilizada em todos os casos, encontrados na forma de acordo e colaboração. Nas situações onde o diálogo não pôde resolver, foi preciso entrar em acordo para demissão.

Na resolução dos conflitos relatados na empresa $\mathrm{A}$, devido ao fato de todos os membros da empresa pertencerem à mesma família, houve uma certa facilidade de comunicação, sendo assim, a gestão de conflitos adotada pela empresa A foi baseada na conversa, no diálogo, e isso é evidenciado a partir dos relatos: 'Quando sentamos e conversamos, como é pai, mãe e filhos, a noite sempre debatemos sobre o problema' e : 'A gestora que é minha mãe, sempre ameniza e questiona o modo como cada um deve trabalhar e o respeito entre nós. Principalmente por sermos família'.

O conflito relatado pelo sujeito $A$, mostra que houve uma alteração negativa na dinâmica da empresa, porém, na visão de $A$, esse conflito trouxe consequências positivas para os funcionários e para a empresa como um todo, porque, a partir dele 'vemos o que estava certo e o que estava errado'. Para finalizar, A afirma que esse conflito teve uma serventia positiva, sendo assim, esse conflito pode ser caracterizado como funcional, pois 'não ficamos com raiva permanente, sempre resolvemos e fica tudo bem. E serve como aprendizado'.

A empresa B, afirma que, no geral os conflitos ocorridos resultam em experiências positivas: 'Numa experiência dessa eu opto por sempre mostrar que aquilo que o outro queria fazer estava errado e que da forma como já vem sendo feito a tempos é o correto, porque já vem dando certo'. Em outro momento, o sujeito diz que 'Quando a mudança é boa, eu aceito'. Apesar da inconsistência entre as afirmações, os resultados são positivos'. Através do aconselhamento, ambas as partes chegaram a um acordo em que ambos ficaram satisfeitos. Dessa forma, na base da conversa, os conflitos gerados são administrados de forma a manter um ambiente cordial. O entrevistado finaliza dizendo: 'Precisamos seguir o lado mais fácil, que não dê prejuízo para ambas as partes e que saiam todos satisfeitos.

Na gestão de conflitos da empresa C, foi necessário o distanciamento, pois chegou-se ao ponto de o conflito tornar-se manifestado: 'Chegamos ao ponto de trocarmos tapas, discussão'. Diante desta situação não foi possível extrair em primeira instância algum resultado positivo. Apesar do evento ter sido caracterizado de forma negativa, o entrevistado afirma que adquiriu aprendizado caso ocorra isso novamente com outra pessoa. $O$ entrevistado enfatizou que é maleável e sempre entendia o lado do funcionário, pois esse era o seu amigo, mas isso não foi o suficiente para evitar o conflito. Neste caso, o conflito foi disfuncional, porque apesar do aprendizado adquirido com a experiência, ele atrapalhou o 
andamento e produtividade da empresa visto que o funcionário precisou ser desligado definitivamente: 'a solução que eu tive foi não trabalhar mais com a pessoa, pois nos desentendemos de fato'.

Na resolução dos conflitos da empresa $D$, diferentemente da empresa $A$, ter um funcionário que faz parte da mesma família dificultou no momento de resolver o conflito. O gestor da empresa D afirmou que, por tratar-se de sua mãe como funcionária, a relação entre família e emprego não estava bem estabelecida, ocasionando uma má interpretação das situações. É possível observar essa dificuldade a partir da fala: 'Mas, infelizmente, por eu ser filha e ela ser mãe, pensou que eu estava colocando ela pra baixo e preferiu sair da empresa'. O sujeito da empresa D afirma que, no geral, existe dificuldade em relação a gestão de conflito na empresa: 'aqui hoje, é o meu marido e as duas pessoas que trabalham lá comigo. Não é fácil resolver não, é sempre com palavras negativas, você vai reclamar, e diz que não foi, que não é assim, sempre entra em contradição'. O sujeito D segue afirmando que o diálogo é uma possibilidade, mas, devido à falta de entendimento em separar as relações, torna-se uma ferramenta incerta: 'É conversando, conversa para lá, primeiro fica chateado, aí você vai de novo, toca no ponto para ver se vai melhorando'.

Ainda de acordo com D, os conflitos apresentados trouxeram, naquele momento, consequências negativas para a empresa, afetando a relação entre os funcionários, que também são familiares, ao ponto de precisar desligar a pessoa da empresa 'passou um tempo chateada de mim, depois voltou a falar normal, porém no mercado ela não trabalha mais', sendo assim, esse conflito pode ser considerado como disfuncional, pois não trouxe nenhum benefício para a empresa ou para a relação entre as pessoas.

Finalmente, a gestão de conflitos na empresa E também está baseada no diálogo, que neste caso, foi uma ferramenta importante e eficaz na resolução dos conflitos, e isso se deve ao fato de existir uma relação familiar entre os funcionários, possibilitando maior facilidade na resolução do conflito: 'eu com minha esposa nos reunimos em casa, e temos uma liberdade muito grande de conversamos, e aí conversamos, nos acertamos, e o dialogo valeu muito'.

Pelo fato de a gestão de conflitos ter sido baseada no diálogo, foi possível identificar que os conflitos apresentados por E foram funcionais, pois geraram consequências positivas e benéficas para a empresa e para seus funcionários 'porque aí surgiu novas ideias'. O sujeito E enxergou o conflito como uma forma de aprendizado. Além disso, foi possível observar que o conflito ajudou a entender dinâmica da empresa, pois a partir dele, os funcionários, que antes erraram, aprenderam e entenderam o que devem fazer 'Então eu desfrutei, depois desse embate, e agora está tudo bem, porque eles colocaram em mente na prática aquilo que devia ser feito'.

\section{Quadro resumo dos conflitos e resoluções}

A partir das análises dos dados coletados em campo, foi possível capturar os conflitos, seus níveis e tipos de resolução para as microempresas familiares participantes do estudo, elementos estes apresentados na tabela 1. 
Tabela 1: Conflitos e soluções identificados em campo.

\begin{tabular}{|c|c|c|c|c|c|}
\hline \multirow{2}{*}{ Empresa } & \multicolumn{3}{|c|}{ Níveis do conflito } & \multicolumn{2}{|l|}{ Resolução } \\
\hline & 10 Percebido & 20 Experienciado & 3 Manifestado & Tipo & Resultado \\
\hline$A$ & INTERPESSOAL & INTRAGRUPO & INTRAGRUPO & COLABORAÇÃO & FUNCIONAL \\
\hline$B$ & INTERPESSOAL & INTERPESSOAL & NÃO & COLABORAÇÃO & FUNCIONAL \\
\hline $\mathrm{C}$ & INTERPESSOAL & INTERPESSOAL & NÃO & ACORDO & DISFUNCIONAL \\
\hline $\mathrm{D}$ & INTERPESSOAL & INTERPESSOAL & INTERPESSOAL & ACORDO & DISFUNCIONAL \\
\hline$E$ & INTRAGRUPO & INTERPESSOAL & INTERPESSOAL & COLABORAÇÃO & FUNCIONAL \\
\hline
\end{tabular}

\section{CONCLUSÕES}

As microempresas desempenham um papel fundamental e necessário na economia brasileira. Grande parte das microempresas existentes são mantidas por membros da mesma família, as chamadas microempresas de gestão familiar. Entretanto, vários tipos de conflitos, em níveis diferentes, são encontrados nesse contexto. A ocorrência desses conflitos pode trazer riscos que afetam de forma negativa a produtividade e o relacionamento entre os membros, trazendo como consequência disso menor produtividade, diminuição de receita e problemas na vida particular, por conta do atrito gerado nas relações familiares.

A origem dos conflitos empresas participantes do estudo se deu a partir da dificuldade em entender as diferenças entre relações de trabalho e relações familiares. A falta desse entendimento causou problemas de ordem hierárquica, pois houve uma dificuldade de interpretação dos papéis desempenhados, onde os funcionários familiares não conseguiam compreender que alguém de sua família ou seu amigo próximo exercia uma função de autoridade na organização.

Os sentimentos negativos e divergências de opiniões que os entrevistados relataram, afetaram na relação entre funcionário e patrão, fazendo com que houvesse uma má execução de funções e de tarefas, chegando, em algumas empresas, até o estágio de desligamento.

A maneira adotada pelas microempresas de gestão familiar para gerenciar e solucionar seus conflitos foi característico, pois o fato de serem microempresas, que têm estruturas mais informais, e vivenciarem a organização com os membros da família possibilitou o diálogo, facilitando, em muitas situações, a resolução positiva do conflito. Por isso, as cinco empresas entrevistadas adotaram o diálogo como ferramenta para a resolução de problemas e conflitos.

Adicionalmente, o diálogo é uma ferramenta que possibilita a identificação, gerenciamento e resolução dos conflitos, proporcionando, também, a aprendizagem, e acordos que beneficiem ambas as partes, mudando o clima organizacional e a dinâmica entre os membros da família.

\section{REFERÊNCIAS}

ABREU, M. L. L.; PIMENTA, E. G.; LUCCA, N.. Empresa familiar: estudos jurídicos. São Paulo: Saraiva, 2014.

ADACHI, P. P. F. S. A.. Gestão de empresa familiar e solução de conflitos. São Paulo: Atlas, 2006.

ALMÉRI, T. M.; BARBOSA, E. G.; NASCIMENTO, A.. Conflitos Organizacionais: os diversos tipos de conflitos interpessoais nas organizações suas causas e efeitos. Revista de

Administração da Fatea, v.9, n.9, p.54-71, 2014.
BARDIN, L.. Análise de conteúdo. 3 ed. Lisboa: Ediçoes 70 2011.

BONETTO, A. L. C. P.; NAUMANN, C.; OLIVEIRA, L. G.. Gestão de conflitos: o papel do gestor no gerenciamento de conflitos. Rev. FAE, Curitiba, n.2, p.153-164, 2017.

BRASIL. Lei complementar n.123, de 14 de dezembro de 2006. Brasília: DOU, 2006. 
CARVALHO, M. M. F.. Gestão de Conflitos: um estudo de caso em uma empresa familiar do setor metalúrgico. 2019.

CHIAVENATO, I.. Gestão de Pessoas: e o novo papel dos recursos humanos na organização. 4 ed. Rio de Janeiro: Elsevier, 2014.

DUBRIN, A J.. Fundamentos do comportamento organizacional. São Paulo: Pioneira Thomson Learning, 2006.

FERNANDES NETO, A. F.. Gestão de conflitos. Thesis, São Paulo, v.2, n.4, p.1-16, 2005.

FERNANDES, R. B.; LEITE, F. I.; TAVARES, A. L.; AZEVEDO, Y. G. P.. Balanço perguntado: Um Instrumento para Análise Econômico-Financeira de Micro e Pequenas Empresas. REMIPE- Revista de Micro e Pequenas Empresas e Empreendedorismo da Fatec Osasco, v.5, n.1, 2019.

GARUFFE, A. F. F.; SANTOS, M. H. C.; MARIANO, T. S.. Os Desafios na Gestão das Micro e Pequenas Empresas Familiares; Pindamonhangaba: Fundação Universitária Vida Cristã, 2017.

LIMÁRCIO, T.; ALVES, L.; LEITE, C. E.; ANTUNES, M. A.; DANIEL, A. L.. A importância da gestão em empresas familiares. In: SIMPÓSIO DE EXCELÊNCIA EM GESTÃO E TECNOLOGIA. Anais. Resende, 2015.

MAMEDE, G.; MAMEDE, E. C.. Empresas familiares: administração, sucessão e prevenção de conflitos entre sócios. São Paulo: Atlas, 2012.

PRODANOV, C. C.; FREITAS, E. C.. Metodologia do Trabalho Científico: Métodos e Técnicas da Pesquisa e do Trabalho Acadêmico. 2 ed. Universidade Feevale, 2013.

NASCIMENTO, M. S.; CARDOSO, S. C.. A visão sociológica do conflito na empresa. Omnes Humanitate: Revista Científica da ESAB, v.2, n.7, p.43, 2012.

OLIVEIRA, R. A.. Gestão estratégica para micro e pequenas empresas. Fema, 2014.

RIBEIRO, A. F. G.; OLIVEIRA, L. C.; ANDRADE, C. C.. Os desafios da liderança na gestão de conflitos. Revista de Administração do Unifatea, v.14, n.14, p.6-219, 2017.

RODRIGUES, I. R.; CASTRO, J. D. B.. A importância das Microempresas (ME) no atual cenário econômico Brasileiro. In: SEMINÁRIO DE PESQUISA, PÓS-GRADUAÇÃO, ENSINO E EXTENSÃO DO CCSEH - SEPE ÉTICA, POLÍTICA E EDUCAÇÃO NO BRASIL CONTEMPORÂNEO, 3. Anais. 2017.

RUFFATTO, J.; PAULI, J.; FERRÃO, A. R.. Influência do estilo de liderança na motivação e conflitos interpessoais em empresas familiares. Rev. Adm. FACES Journal, Belo Horizonte, v.16, n.1, p.29-44, 2017.

RUZZÃO, A. P. A.; SANTOS, J. E.; AZADINHO, L. Z.. O planejamento estratégico como ferramenta: estudo sobre a eficiência das micro e pequenas empresas brasileiras.

Administração de Empresas em Revista, Curitiba, v.16, n.17, p.50-68, 2017. DOI:

http://doi.org/10.6084/m9.figshare.5410522

SILVA, A. J. A.; MUNHOZ J. P.; MUNHOZ J. A.. Administração de Conflitos nas Organizações: Complexidade e Desafios. Cadernos da Escola de Negócios, Curitiba, v.1, n.13, 2015.

SILVA, A. B.; BRASIL, Â. S.; ALVARENGA, L. M. S.; SANTOS, S. $M$.. Desafios enfrentados pelas micro e pequenas empresas no Brasil. Rev. Conexão Eletrônica, Três Lagoas, v.12, n.1, 2015.

SILVEIRA, J. I. F.. A aprendizagem organizacional em microempresas. Centro Universitário de Brasília, 2011.

SOUZA, G. P.; SANTOS, K. Z.; VASCONCELLOS, M. O.. Conflitos Interpessoais no Ambiente Organizacional. FOCO: revista de Administração e Recursos Humanos da Faculdade Novo Milênio, v.7, n.11, p.43-58, 2014.

VELLOSO, S. P., GRISCI, C. L. I.. Governança corporativa e empresas familiares em processo sucessório: a visão de consultores e de famílias empresárias. Revista Base (Administração e Contabilidade) da UNISINOS, v.11, n.4, 2014.

WERNER, R. A.. Família \& negócios: um caminho para o sucesso. São Paulo: Manole, 2004.

A CBPC - Companhia Brasileira de Produção Científica (CNPJ: 11.221.422/0001-03) detém os direitos materiais desta publicação. Os direitos referem-se à publicação do trabalho em qualquer parte do mundo, incluindo os direitos às renovações, expansões e disseminações da contribuiç̃o, bem como outros direitos subsidiários. Todos os trabalhos publicados eletronicamente poderão posteriormente ser publicados em coletâneas impressas sob coordenação da Sustenere Publishing, da Companhia Brasileira de Produção Científica e seus parceiros autorizados. Os (as) autores (as) preservam os direitos autorais, mas não têm permissão para a publicação da contribuição em outro meio, impresso ou digital, em português ou em tradução. 